\title{
A DEGRADAÇÃO DO PATRIMÔNIO HISTÓRICO E CULTURAL
}

\author{
TOSHIO MUKAI
}

I. Introdução - 1. De Limitações Urbanísticas a Questão Ambiental - 2. De como o Patrimônio histórico e cultural vem sendo preservado no Brasil. O princípio da função social da propriedade - II. A visão $e$ o regime jurídico moderno da preservação do Patrimônio histórico e cultural no Brasil. - III. A degradação do meio ambiente cultural e os meios de se combatê-la. - IV. A proteção do bem de valor histórico e cultural depende do tombamento? - V. Conclusão

\section{Introdução}

1. De Limitações Urbanísticas a Questão Ambiental

O estudo do tema "patrimônio histórico, artístico e cultural" começa entre nós no campo do urbanismo.

Nesse sentido, a afirmação de Alcides Greca: "teniendo el Município faculdades policiales, podrá exercelas también por médio de reglamentaciones em todos aquellas matérias y atividades que lê son inherentes por raziones de estética, de seguridad, de salud pública, de transito, de servicios públicos, de moralidad, de caráter social y econômico, cultural y histórico".'

Daí porque Hely Lopes Meirelles, "diante das novas exigências do bem-estar social", classificou as limitações urbanísticas em "cinco grupos bem distintos, consoante o interesse público tutelado: limitações de proteção ao domínio público; de proteção à salubridade urbana; de proteção à funcionalidade urbana; de proteção à segurança urbana; $e$ de proteção estética, paisagística e monumental". ${ }^{2}$

1 GRECA, Alcides. "Regime legal de lās construciones" 1956, p. 40.

2 MEIRELLES, Hely Lopes. “ $O$ direito de construir”, São Paulo, Rev. Dos Tribs., 1965, p. 119. 
Essa inclusão, o autor nos apresenta com as seguintes palavras: "A proteção paisagistica e monumental enquadra-se perfeitamente nas limitações urbanísticas de defesa estética da cidade e suas adjacências, como elemento de recreação espiritual e fator de educação artística da população." 3

E completa a fundamentação: "a preservação dos recantos naturais, de vistas panorâmicas, da vegetação nativa que caracteriza nossa flora e dos ambientes antigos que guardam as nossas tradições, enquadra-se no poder de polícia administrativa, incumbido, não só da tutela dos bens materiais, mas e sobretudo dos valores estéticos e espirituais que integram o patrimônio artístico e cultural da nação. O urbanismo não despreza o ambiente natural, nem relega a tradição". ${ }^{4}$

Nos tempos atuais, já se fala em "meio ambiente cultural".

José Afonso da Silva", após conceituar o meio ambiente como "a interação do conjunto de elementos 'naturais, artificiais e culturais' que propiciem o desenvolvimento equilibrado da vida em todas as suas formas", acrescentando que " $a$ integração busca assumir uma concepção unitária do ambiente, compreensiva dos recursos naturais e culturais", mostra a existência de três aspectos do meio ambiente: o meio ambiente artificial (espaço urbano construído - conjunto de edificações e equipamentos públicos: ruas, praças, áreas verdes etc ) o meio ambiente cultural integrado pelo patrimônio histórico, artístico, arqueológico, paisagístico, turístico, que, embora artificial, em regra, como obra do homem, difere do anterior (que também é cultural) pelo sentido de valor especial que adquiriu ou de que se impregnou; o meio ambiente natural, ou físico (solo, água, ar, flora e fauna).

Portanto, o patrimônio cultural, artístico e histórico, hoje, entre nós, faz parte do meio ambiente, e, como tal, como objeto de estudo, não pode deixar de ser considerado como um assunto específico pertinente ao meio ambiente.

2. De como o Patrimônio histórico e cultural vem sendo preservado no Brasil. $O$ princípio da função social da propriedade

Em acórdão célebre de 1942, o nosso Supremo Tribunal Federal ${ }^{6}$, em reunião plenária deixou escrito:

"A antiga noção de propriedade, que não vedava ao proprietário senão o uso contrário às leis e regulamentos, completou-se com o da sua utilização posta ao serviço do interesse social; a propriedade não é legítima senão quando se traduz por uma realização vantajosa para a sociedade."

Do corpo do mesmo acórdão consta:

3 MEIRELLES, Hely Lopes. Op. cit., p. 12.

4 Idem, p. 133.

5 SILVA, José Afonso. Direto Ambiental Constitucional, $3^{a}$ ed., Ed. Malheiros, São Paulo, 2000, pp. $20 / 21$.

5 Acórdão de 17.06.1942, Rev. dos Tribunais, São Paulo (147:785). 
"A propriedade social concretiza uma concepçāo jurídica aplicada para fundamentar a legalidade da proteção aos monumentos históricos e objetos de arte, indicando a existência de um degrau do desenvolvimento progressivo do direito de propriedade em um sentido cada vez menos individual, diz-se que em tais monumentos e objetos, em poder do particular, existem duas partes distintas: a intelectual - ou seja, o pensamento do artista, o ideal que ele encarnou, e o material - isto é, esta mesma forma que lhe serviu para fixar o seu pensamento, o seu ideal. A primeira pertence à sociedade que a deve proteger; somente a segunda pertence à propriedade privada, gravada de servidão...".

Essa belíssima lição nos mostra um ponto saliente: os bens considerados patrimônio cultural da Nação - histórico, paisagístico e natural - são ônus real legal, passando desde o tombamento (inscrição em um dos livros do tombo) a se constituírem em propriedade limitada e não plena, segundo distinção do Código Civil.

A constitucionalidade do Decreto-lei $n^{\circ} 25$ (que institui, em nível nacional, o tombamento de bens considerados patrimônio histórico e cultural) já foi questionada perante o S.T.F, que, segundo informa José Cretella $\mathrm{Jr}^{7}{ }^{7}$, manifestou-se no sentido de que "diante do dispositivo expresso da Constituição de 1937, o Dec. Lei no 25 é inatacável, constitucional", quando apreciou a hipótese "leading case" no Brasil, a respeito do assunto, ou seja, o célebre caso do tombamento do famoso conjunto arquitetônico do "Arco de Telles" no Rio de Janeiro.

II. A visão e o regime jurídico moderno da preservação do Patrimônio histórico e cultural no Brasil

Helita Barreiro Custódio 8 escreveu: "Para os fins protecionistas, a noção de meio ambiente é muito ampla, abrangendo todos os bens naturais e culturais de valor juridicamente protegidos, desde o solo, as águas, o ar, a flora, a fauna, as belezas naturais e artificiais, o ser humano, ao patrimônio histórico, artístico, turístico, paisagistico, monumental, arqueológico, além das variadas disciplinas urbanísticas contemporâneas".

Sebastião Valdir Gomes ${ }^{9}$, no mesmo sentido, assevera que hoje há um consenso no que tange à especificação do ambiente cultural como integrante do conceito de meio ambiente como um todo.

Já a Constituição de 1988 reza:

Constituem patrimônio cultural brasileiro os bens de natureza material e imaterial, tomadas individualmente ou em conjunto, portadores de referência à identidade, à ação, à memória dos diferentes grupos formadores da sociedade brasileira, nos quais se incluem:

7 CRETELLA, José Jr. "Regime Jurídico do tombamento", RDA, 112/57, abr/jun de 1973.

8 Legislação Ambiental no Brasil — Rev. Direito Civil, Imobiliário, Agrário e Empresarial, São Paulo, n 76,1996, p. 56.

9 Novas Questões de Direito Ambiental, Rev. Dos Tribs., São Paulo, nº 744, p. 73, 1997. 
"I. as formas de expressão;

II. os modos de criar, fazer e viver;

III. as criações científicas, artísticas, arqueológicas e tecnológicas;

IV. as obras, objetos, documentos, edificações e demais espaços destinados às manifestações artístico-culturais;

V. os conjuntos urbanos e sítios de valor histórico, paisagístico, artístico, arqueológico, paleontológicos, ecológicos e científicos.

$\S 1^{\circ}$ - O Poder Público, com a colaboração da comunidade, promoverá e protegerá o patrimônio cultural brasileiro, por meio de inventários, registros, vigilância, tombamento e desapropriação, e de outras formas de acautelamento $e$ preservação.

$\S 2^{\circ}$

$\S 3^{\circ}$ - A lei estabelecerá incentivos para a produção e o conhecimento de bens $e$ valores culturais.

$\S 4^{\circ}$ - Os danos e ameaças ao patrimônio cultural serão punidos, na forma da lei".

Portanto, a atual Constituição coloca no mesmo pé de igualdade, a proteção dos valores históricos e culturais e o meio ambiente como um todo.

E, nesse diapasão, convém indicar a legislação brasileira básica existente, que visa dar cumprimento a tais preceitos constitucionais:

a) O Decreto-lei $n^{\circ} 25 / 37$, que continua em vigor, recepcionado que foi pela Constituição vigente;

b) A Lei $n^{\circ} 9.790$, de 23.03 .1999 , que dispõe sobre a promoção de cultura através de organizações da sociedade civil de interesse público (OSCIPs);

c) A Lei $n^{\circ} 3.924$, de 26.07.1961, que dispõe sobre os monumentos arqueológicos e pré-históricos;

d) O Decreto $\mathrm{n}^{\circ} 3.551$, de 04.08.2000, que institui o registro de bens culturais de natureza imaterial que constituem patrimônio cultural brasileiro e cria o Programa Nacional do Patrimônio Imaterial;

e) As Leis $n^{\circ} 7.505$, de 02.07.1986 (Lei Sarney) e n 8.313, de 23.12.1991 (Lei Rouanet) que dispõem sobre benefícios fiscais concedidos a operações de caráter cultural ou artístico.

f) O Decreto-lei $n^{\circ} 1.809$, de 23.11.1940 - dispõe aceitação e aplicação de donativos particulares ao Serviço do Patrimônio Histórico e Artístico Nacional.

g) $O$ Decreto-lei $n^{\circ} 2.848 / 1940$ (C. Penal) que no seu art. 165 tipifica como crime, "destruir, inutilizar ou deteriorar coisa tombada pela autoridade competente. Pena: detenção de seis meses a dois anos e multa".

h) O Decreto-lei $n^{\circ} 3.365$, de 21.06 .1941 , que coloca como finalidade da desapropriação a preservação e conservação dos monumentos históricos e artísticos.

i) Lei ${ }^{\circ} 9.605$, de 12 de fevereiro de 1998 (crimes ambientais).

Art. 63 - Alterar o aspecto ou a estrutura de edificação ou local especialmente protegido por lei, ato administrativo ou decisão judicial, em razão de seu valor paisagístico, ecológico, turístico, artístico, histórico, cultural, religioso, arqueológico, etnográfico ou monumental, sem autorização da autoridade competente ou em desacordo com a concedida. 
Pena - reclusão, de um a três anos, e multa.

Art. 64 - Promover construção em solo não edificável, ou no seu entorno, assim considerado em razão de seu valor paisagístico, ecológico, artístico, histórico, turístico, cultural, arqueológico, etnográfico ou monumental, sem autorização da autoridade competente ou em desacordo com a concedida.

Pena - detenção, de seis meses a um ano, e multa.

Outras normas ainda existem sobre o patrimônio histórico e cultural que deixamos de citar, posto que não é o escopo do presente trabalho, tal finalidade.

O regime jurídico do patrimônio histórico e cultural, entretanto, já conta com uma vasta legislação sobre diversos aspectos que interessam à sua preservação.

III. A degradação do meio ambiente cultural e os meios de se combatê-la.

No Brasil, não obstante a vasta legislação existente sobre o assunto, a preservação, conservação e repressão aos delitos cometidos contra o nosso patrimônio histórico e cultural é quase inexistente.

Embora os órgãos e/ou entidades da União, dos Estados e de alguns municípios tenham se esforçado para o cumprimento de suas missões, geralmente eles não contam com respaldo financeiro e de pessoal para uma eficaz proteção do patrimônio cultural e artístico.

No geral, a degradação do nosso patrimônio cultural se dá pelas seguintes vias e razões:

a) escassa vigilância do Poder Público na fiscalização dos bens tombados (a mídia constatou, recentemente, o roubo de inúmeras imagens e objetos de valor histórico ou artístico, retirados normalmente de igrejas e/ou museus);

b) dificuldade de preservação dos objetos e imóveis tombados;

c) inação do Poder Público (Executivo) quanto a tombamentos de bens que contenham valor histórico, paisagístico, arqueológico, histórico e/ou cultural.

Antes de adentrarmos nos diversos modos e análise dos instrumentos judiciais disponíveis para solucionar esses tipos de degradações, convém citar e analisar o instituto (administrativo) por excelência, de proteção dos bens do patrimônio histórico, artístico e cultural, que é o tombamento.

Define o tombamento, Maria Coeli Simões Pires ${ }^{10}$, como “o ato final de um procedimento administrativo, resultante do 'poder discricionário' da Administração, por via do qual o Poder Público institui uma servidão administrativa, traduzida na incidência de regime especial de proteção sobre determinado bem, em razão de suas características especiais, integrando-se em sua gestão com a finalidade de atender ao interesse coletivo de preservação cultural".

$\mathrm{O}$ art. $1^{\circ}, \S 1^{\circ}$ do Decreto-lei $n^{\circ} 25 / 37$ estatui:

10 "Da Proteção ao Patrimônio Cultural", Del Rey, B.H., 1994, p. 278. 
“§ $1^{\circ}$ - Os bens a que se refere o presente artigo só serão considerados parte do patrimônio histórico e artístico nacional, depois de inscritos separada ou agrupadamente 'num dos quatro livros do Tombo, de que trata o art. $4^{\circ}$ desta' Lei'."

Portanto, tombar é fazer incidir sobre o bem considerado de valor histórico, artístico etc. um regime jurídico de utilização restrita do bem, impondo-lhe um gravame que acompanhará o bem para sempre (pode haver, em certas circunstâncias, o cancelamento do tombamento).

Em suma: um bem que contenha um valor histórico, artístico etc., deve ser tombado, e resguardado como bem de interesse público, sendo crime, a sua destruição ou deteriorização (art. 165 do C.P., arts. 63 e 64 da Lei n ${ }^{\circ}$ 9.605/98).

A primeira questão que surge é a seguinte: o ato de tombamento é um ato discricionário ou vinculado?

Já vimos que Maria Coeli Simões Pires entende que se trata de um ato discri-

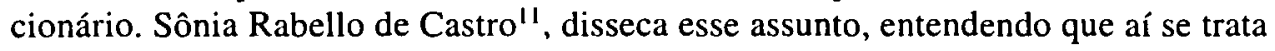
de discricionariedade técnica, havendo a possibilidade de se verificar que a aplicação dos conceitos é baseada em estudo técnicos coerentes e sistemáticos.

No famoso caso do "Arco de Telles", considerado o caso padrão na nossa jurisprudência sobre o tombamento, o S.T.F. firmou a tese de que, nos casos de tombamento, cabe ao Judiciário examinar-lhe o mérito. Não quanto à oportunidade e conveniência, que são critérios políticos; mas quanto à motivação, pois o tombamento é um ato administrativo vinculado. Em virtude do texto constitucional que fala em "proteção especial pelo poder público", surge com realce o poder-dever, princípio especial do Direito Administrativo a ser considerado na atividade administrativa concernente ao assunto.

E, assim, já se expressou o S.T.F.:

Ao Judiciário cabe decidir se o imóvel, inscrito no Serviço do Patrimônio Histórico e Artístico Nacional, "tem ou não" valor histórico ou artístico, não se limitando a sua competência à verificar, apenas, se foram observadas as formalidades". "... verificada a procedência do valor histórico do imóvel de domínio particular como integrante do conjunto arquitetônico, subsiste o tombamento compulsório, com as restrições que dele decorrem para o direito de propriedade, sem necessidade de desapropriação". ${ }^{12}$

Quanto à conservação e reparações do bem tombado, segundo o Decreto-lei ${ }^{\circ}$ 25, cabem ao proprietário do bem:

a) não destruir, demolir ou mutilar o bem inscrito;

b) as reparações necessárias à conservação são feitas pelo proprietário, ouvido o SPPHA;

c) se o proprietário não dispuser de recursos, poderá o órgão efetuar a conservação ou desapropriar o imóvel.

Outros meios de proteção e de reparações da degradação do meio ambiente cultural, são indicados.

11 "O Estado na Preservaçāo de Bens Culturais", Renovar 1991, pp. 88/89.

12 Revista Forense, Rio de Janeiro, (98):586. 
Existem diversos instrumentos jurídicos que se prestam a evitar ou reprimir a degradação do meio ambiente cultural.

O primeiro deles é a Ação Popular, que se destina a anular ato lesivo ao patrimônio público, à moralidade administrativa, ao meio ambiente e ao Patrimônio histórico e cultural..." (art. $5^{\circ}$, inc. LXXIII).

A Lei n ${ }^{\circ} 7.347$, de 24.07.1985 (Lei de Ação Civil Pública), no seu art. $1^{\circ}$ reza: "Regem-se pelas disposições desta Lei, sem prejuízo da ação popular, as ações de responsabilidade por danos morais e danos patrimoniais causados: I - ao meio ambiente; III - a bens e direitos de valor artístico, estético, histórico e paisagistico".

O mandado de segurança coletivo (art. $5^{\circ}, \mathrm{LXX}$ ) poderia ser utilizado, também, em casos restritos. E o mandado de injunção, quando houver falta de norma regulamentadora prevista em lei ou na Constituição, necessária à proteção do patrimônio histórico e artístico.

Além desses instrumentos judiciais de proteção do patrimônio cultural, devemos considerar as ações administrativas dos três níveis de Governo nessa proteção. Portanto, estamos a falar das competências dos níveis de Governo nessa matéria.

Em primeiro lugar, há que relembrar que a Constituição de 1988, no seu art. 216, $\S 1^{\circ}$ determinou que: "o Poder Público, com a colaboração da comunidade, promoverá e protegerá o patrimônio cultural brasileiro, por meio de inventários, registro, vigilância, tombamento e desapropriação, e de outras formas de acautelamento e preservação".

Portanto, a competência para atuar em relação à matéria pertence aos três níveis de Governo. Como há muito tempo declarou Carlos Medeiros Silva, ex-Ministro do S.T.F., em parecer de 27.01.1974: "A competência conferida ao Serviço Federal para o tombamento de bens não exclui a de serviços congêneres instituídos para o mesmo fim, pelos estados e municipios ${ }^{13}$."

Com fundamento na Constituição de 1988, também os três níveis de Governo (além do Distrito Federal), têm competência para legislar e atuar na proteção e preservação do meio ambiente cultural - art. 216 da C. F.

Assim, pelo art. 24, inciso VII, a União, os Estados, o Distrito Federal, têm competência para legislar sobre assuntos relativos à proteção do patrimônio histórico, cultural, artístico, turístico e paisagístico. As normas da União são de cunho geral $\left(\S 1^{\circ}\right)$ e as dos Estados, suplementares das gerais da União e/ou específicas.

A competência do Município para legislar sobre o assunto cai no "interesse local" (art. 30, I da C. F.). Idem para atuar.

Contudo, para atuar administrativamente, exercendo as atribuições previstas no art. 216 da C.F., inclusive, efetuando tombamento, todos os níveis de Governo haurem suas competências autônomas e exclusivas da própria disposição constitucional, já que o Brasil é um Federação, nos termos do art. 18 da C. F.

13 SILVA, Carlos Medeiros. "A competência conferida ao serviço federal para o tombamento..." (parecer), RDA, 120/459-78,1975. 
Destarte, a União efetua a proteção e preservação de bens de interesse artístico, cultural nacional; os Estados-membros, de bens de interesse regional-estadual e os Municípios, de bens de valor histórico, artístico e cultural local.

Quanto à competência comum, pelo art. 23, não compete a cada um dos níveis de Governo atuar isolada e concomitantemente sobre um bem de valor histórico ou artístico de que nível for. Cabe aqui apenas a ação administrativa em termos de cooperação (convênios), tendo em vista o sentido e o alcance do "caput" (pela expressão comum), dada pelo Parágrafo único da disposição: "Lei Complementar fixará normas de 'cooperação entre a União e os Estados', o Distrito Federal e os Municipios, tendo em vista o equilíbrio do desenvolvimento e do bem-estar em âmbito nacional".

A expressão "cooperação" nos mostra que aqui o Constituinte abraçou a tese do federalismo cooperativo. Portanto, quando o art. 23 admite a ação administrativa dos diversos níveis de Governo sobre as matérias que indica (III - proteger os documentos, as obras e outros bens de valor histórico, artístico e cultural, os monumentos, as paisagens naturais notáveis e os sítios arqueológicos) quer que haja convênios e/ou cooperações entre os diversos órgãos de proteção do patrimônio cultural, para que uns colaborem com os outros. Mas, evidentemente, não poderá haver três ou quatro atos de tombamentos sobre um mesmo bem de valor artístico, histórico ou cultural, porque se o referido bem contiver um valor puramente local, somente o Município poderá tombá-lo; se o valor for estadual, somente o Estado de que se trate poderá tombar o bem; assim também ocorre com a União.

Numa única hipótese isto poderia ocorrer que o bem contivesse, ao mesmo tempo, valor nacional, regional-estadual e municipal.

\section{A proteção do bem de valor histórico e cultural depende do tombamento?}

Maria Sylvia Zanella Di Pietro ${ }^{14}$, observa que "o patrimônio histórico e artístico nacional está definido no artigo $1^{\circ}$ do Decreto-lei $n^{\circ} 25$, de $30.11 .37[\ldots]$

Além da proteção administrativa, por meio do tombamento, disciplinado por esse Decreto-lei, o patrimônio histórico ou artístico pode ser defendido por meio da ação popular ou da ação civil pública. Não é exigível o prévio tombamento como condição da ação; aliás, são precisamente os bens ainda não tombados os que mais necessitam de proteção. É curioso que, se em juízo ficar reconhecido o valor patrimonial do bem, para fins de proteção, ter-se-á um caso típico de tombamento resultante de decisão judicial".

Rui Arno Richter ${ }^{15}$ cita, no mesmo sentido, ou seja, que seja possível o tombamento judicial, Edna Cardozo Dias.

14 DI PIETRO, Maria Sylvia. "Direito Administrativo" 6ed., São Paulo, 1996, pp. 535/536. 15 RICHTER, Rui Anno. "Meio Ambiente Cultural - Omissão do Estado e Tutela Judicial", Ed. Juruá, 1999, Curitiba. 
O mesmo autor (Rui Arno Richter) nos traz passagens de Hely Lopes Meirelles, que, a nosso ver coloca a questão da proteção dos bens de valor histórico e cultural de maneira correta, ou seja, não se trata de o Judiciário efetuar, diretamente, o tombamento do bem, que somente o Executivo e o Legislativo podem fazê-lo.

Vejamos a assertiva do saudoso mestre: "Quando o Poder executivo não toma as medidas necessárias para o tombamento de um bem que reconhecidamente deve ser protegido em face de seu valor histórico ou paisagístico, a jurisprudência tem entendido que, mediante provocação do M.P. (ação civil pública) ou de cidadão (ação popular), o judiciário pode determinar ao Executivo que faça a proteção ${ }^{16}$."

E, o mesmo autor, em outro lugar aduz: "Quanto aos bens a serem protegidos $e$ ao próprio meio ambiente não há necessidade que estejam 'tombados' bastando que haja interesse público na sua preservação, mesmo porque o 'tombamento não é condição da ação' ${ }^{17}$."

Rui Arno Richter ${ }^{18}$, após analisar vários julgados dos nossos Tribunais, especialmente do E. Tribunal de Justiça de São Paulo, assevera que "dessa análise se verificou o caráter ainda controvertido da admissibilidade da decisão judicial como forma de acautelamento e preservação do bem cultural assim não declarado por meio de lei ou ato administrativo, embora, na maioria dos precedentes encontrados, a resposta haja sido positiva, afigurando-se como posicionamento mais adequado aos ditames constitucionais que regem a matéria e à evolução normativa e doutrinária atinente à tutela jurisdicional dos interesses ou direitos difusos, conforme se passa a sustentar em conclusão".

Para nós, o Judiciário não deve declarar um bem como tendo caráter e valor histórico ou cultural. $\mathrm{Na}$ ação civil pública, ele deve, com fulcro no art. $3^{\circ}$ impor uma obrigação de fazer ao Poder Executivo, ou seja, de tombar um bem em relação ao qual o Judiciário entenda estar presente o caráter histórico ou cultural. Pela ação popular, visa-se anular ato lesivo ao patrimônio histórico e cultural. Pelo mandado de segurança coletivo, pode-se impedir atos do Poder Público que venham a degradar o meio ambiente cultural. Pelo mandado de injunção, obriga-se o Poder Legislativo a regulamentar aspectos atinentes à proteção, pelo tombamento ou não, dos bens de valor cultural.

\section{Conclusão}

A proteção e preservação dos bens de valor histórico, artístico e cultural conta com todo o instrumental jurídico e judicial necessários para a sua efetivação. Somente não têm contado com a vontade política para que tal ocorra efetivamente.

16 MEIRELLES, Hely Lopes. “Direito de Construir”, 6ª ed., São Paulo, Ed. Malheiros, 1994, p. 128.

17 MEIRELLES, Hely Lopes. “Direito Administrativo Brasileiro" $2^{n}$ ed., São Paulo, Ed. Madeiros, 1997, p.144.

18 ob. cit. p. 136. 


\section{Família e Igualdade}

Carlos David S. Aarão Reis

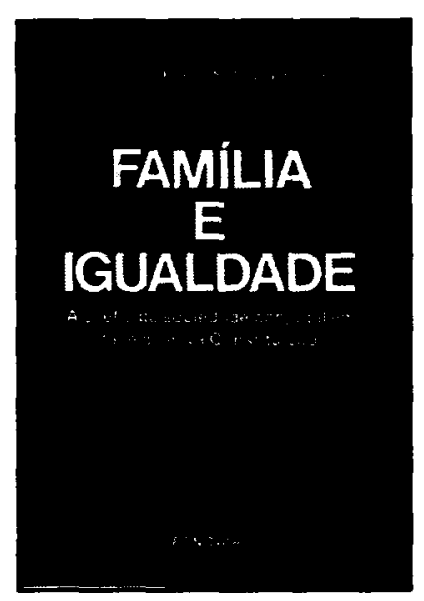

A leitura deste livro fixa, com muita propriedade, a noção de um tema em que muitos falam e poucos assimilam: a igualdade. Enfrentando a questão proposta de forma definitiva, com rigorosa competência e absoluto domínio da doutrina e valendo-se, ainda, de impecável metodologia. Esta obra representa admirável contribuição às letras jurídicas nacionais.

Ref. 0043

Form. 14x21
Brochura 1992
134 págs.

\section{Filosofia do Direito}

Nelson Saldanha

Este livro apresenta, dentro de uma linha temática bastante ampla e abrangente, os temas fundamentais da filosofia do direito. Sem recorrer a uma exposição puramente histórica das matérias, que em tantos casos substitui a reflexão sistemática, a obra se baseia contudo sobre um tratamento substancialmente histórico dos problemas, vistos sob angulaçāo didática e ao mesmo tempo pessoal. Incluindo as questōes epistemológicas, as ontológicas e as axiológicas, o livro conduz a uma série de itens sobre hermenêutica jurídica, envolvendo o hoje tāo discutido tema das normas e dos princípios.

$\begin{array}{lll}\text { Ref. } 0159 & \text { Brochura } & 236 \text { págs. } \\ \text { Form. 14x21 } & 1998 & \end{array}$

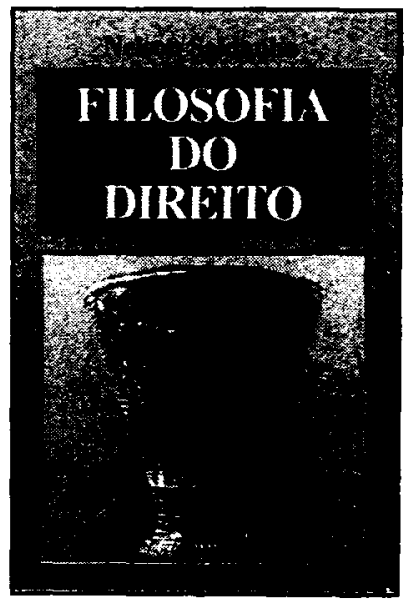

